\title{
CORRECTION
}

\section{Correction to: lleocolic anastomosis after right hemicolectomy: stapled end-to-side, stapled side-to-side, or handsewn?}

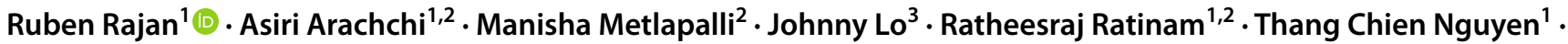 \\ William M. K. Teoh ${ }^{1,2}$. James Tow-Hing Lim ${ }^{1} \cdot$ Hanumant Chouhan ${ }^{1,2}$
}

Published online: 17 February 2022

(c) Crown 2022

Correction to: International Journal of Colorectal Disease https://doi.org/10.1007/s00384-022-04102-0

In the original version of this article, the author name James How-Ting Lim should have been written as James Tow-Hing Lim.

The original article has been corrected.

Publisher's Note Springer Nature remains neutral with regard to jurisdictional claims in published maps and institutional affiliations.

The original article can be found online at https://doi.org/10.1007/ s00384-022-04102-0.

Ruben Rajan

rubenrajan@gmail.com

1 Department of Colorectal Surgery, Dandenong Hospital, Monash Health, 135 David Street, Dandenong, VIC 3175, Australia

2 School of Clinical Sciences at Monash Health, Monash University, Melbourne, VIC, Australia

3 School of Science, Edith Cowan University, Perth, WA, Australia 